\title{
Prevalence of Obesity among Type 2 Diabetic Patients: Non-Smokers Housewives Are the Most Affected in Jeddah, Saudi Arabia*
}

\author{
Balkees Abed Bakhotmah \\ Department of Nutrition \& Food Sciences, The Art and Design College, King Abdulaziz University, Jeddah, Saudi Arabia \\ Email: hbaab1961@yahoo.com
}

Received December 4, 2012; revised January 5, 2013; accepted February 3, 2013

\begin{abstract}
Objective: To identify the high risk group for developing obesity among a cohort of Saudi diabetic patients. Methods: A cross sectional study on a random sample of known type 2 diabetic patients who were visiting seven primary health care centers in Jeddah, Saudi Arabia was conducted. Participants were categorized according to their Body Mass Index BMI into 4 groups. Prevalence of obesity was correlated to patients' gender, age, smoking, educational level and employment status to identify the significant ones. Results: A total of 723 diabetics were included. Males to females' ratio were almost equal (50.8\% and 49.2\% respectively). The mean BMI of group was $29.3 \pm 6.1$. Only $(21.9 \%)$ of the studied diabetics were in their ideal range of body weight. The remaining was almost equally categorized as overweight or obese. More than one third (38.3\%) were obese; among the obese: $22.4 \%$ had mild obesity, and $15.9 \%$ severe obesity. Percentage of severely obese females were almost triple that of males. The housewives were the least to have normal BMI ratio (15.2\%). According to the calculated BMI it is found that being a non-smoker housewife is the significant predicting factor for being obese $\mathrm{p}<0.05$. Conclusion: Prevention and educational programs should target non-smokers housewives Saudi diabetic patients who are at higher risk for developing obesity.
\end{abstract}

Keywords: Diabetes; Overweigh; Obesity; Housewives; Saudi

\section{Introduction}

Obesity is a major global public health problem and one of the important risk factors for type 2 diabetes and cardiovascular diseases. During last two decades there has been dramatic increase in obesity rates all over the globe including Saudi Arabia (SA) and adjacent Co-operation Council of the Arab States of the Gulf (GCC) [1-3]. The changes in prevalence rates of overweight, obesity and other related metabolic diseases, particularly diabetes mellitus DM [4,5], were attributed to the major sociocultural and lifestyle $[1,4]$ changes which accompanied an overall increase of per capita income and recent modernization of Middle Eastern oil countries [6], the promotion of unhealthy fast foods [7], the recent changes in Saudi diet both in quantity and quality $[4,7,8]$ and increasing rates of physical inactivity which reached rates ranging between $43.3 \%$ - 99.5\% [9]. Reported overall prevalence rates of overweight and obesity in adults in GCC countries were $25 \%-50 \%$ and $13 \%-50 \%$, respectively [1]. Most of the studies from GCC reported higher prevalence rates of obesity in females $[10,11]$, but few tested differences by sex [1].

"Conflict of Interests: The author declares no conflict of interest.
This trend of increasing prevalence rates of overweight and obesity was linked to the increasing incidence of type 2 diabetes among the GCC populations $[1,8,12]$. Data accumulated have confirmed that the epidemic of type 2 diabetes is mainly affecting Saudi Arabia SA where the prevalence rate of DM among adults increased from $4 \%$ to up to $30 \%$ over the last 30 years $[1,12]$. Prevalence of overweight and obesity among diabetic patients was also subject of few studies in different provinces of SA $[5,12,13]$. All studies showed significantly higher prevalence rates of both overweight and obesity among diabetics than non-diabetics $[5,13]$ and relatively higher rates among females' diabetic patients [12]. However, none of the reported studies aimed to define the highest risk group for developing obesity among type 2 diabetic patients.

The current study aimed to identify the high risk group for developing obesity among a cohort of Saudi diabetic patients in Jeddah, SA as a step forward for targeting those patients in future prevention and education programs.

\section{Methodology}

The current cross section study was conducted in Jeddah 
city, the second largest city in Saudi Arabia SA over a period of 12 weeks in the year 2009 (20 April-12 July). In Jeddah, there are 40 primary health care PHC centers. A total of 22,000 diabetic patients are registered and regularly visiting these centers. The 40 PHC centers are distributed across the city and categorized into seven geographical sectors. In each sector there are $5-7$ centers. From each sector one center was chosen randomly. The targeted sample was to recruit 70 male and 70 female known diabetic patients - from each center during the study period. A multistage proportionate random selection of 723 diabetic patients from the seven randomly selected PHC centers was pursued; the diabetic patients attending these centers were interviewed (convenient sampling) till completion of the quota assigned proportionately for the selected centers.

All patients enrolled were known type 2 diabetics for at least one year duration who were regularly attending of the assigned PHC center. A pre-designed questionnaire was used to record patients' gender, nationality, age, educational status, working status, smoking history and various treatment regimens for diabetes. Smoking was defined as active smoking of cigarettes and/or "sheeshah" within the last month. Working status was defined as employed i.e. has a current job, unemployed, retired or housewife. Housewife is a woman who is unemployed and taking care of her family fully or partially with assistance of housemaid.

The weight and height was measured for each patient, and the Body Mass Index (BMI) (BMI; body weight $(\mathrm{kg}) /$ body height $\left.(\mathrm{m})^{2}\right)$ was calculated and classified according to the world health organization criteria based on the BMI values [14] except for obese class 2 and 3 which were combined together as severe obesity category. Therefore, patients were categorized into 4 groups: Normal if BMI is less than 25, overweight 25-less than 30 , mild obesity 30-less than 35 and severe obesity 35 and more. Prevalence's rates of obesity were correlated to all patients' characteristics including gender, age, educational level, working status, smoking history and various treatments.

This study was conducted according to the guidelines of the Declaration of Helsinki [15] and under the approval of the Bio-Ethics Committee of King Abdulaziz University Hospital. All data were coded and entered in a personal computer. Statistical analysis was performed using Statistical Package for Social Science (SPSS) program, version 16. Quality control was ensured at the stages of coding and data entry. Data were presented using descriptive statistics in the form of frequencies and percentages for qualitative variables, and mean and standard deviation for quantitative variables. Qualitative variables were compared using chi-square test. The level of statistical significance was set at $\mathrm{p}<0.05$ throughout the study.

Ordinal logistic regression was conducted to examine predictors for obesity among the diabetic patients, where the ordered categorical BMI categories were set as outcome and both smoking status and employment in addition to gender were assigned as explanatory variables. The test of parallelism was performed to judge the model adequacy. Provided that the null hypothesis for the test states that the corresponding regression coefficients are equal across all levels of the outcome variable, the alternative hypothesis states that the corresponding regression coefficients are different across all levels of the outcome variable [16]. The chi-square test result $\left(X^{2}=167.693\right.$ with d.f. of 12 , and $p=0.129$ ) indicated that there was no significant difference for the corresponding regression coefficients across the response categories, suggesting that the model assumption of parallel lines was not violated in the complete model.

\section{Results}

A total of 747 known diabetics were studied. The great majority of the group was Saudis (91.7\%), and there was an almost equal distribution in the study group of both genders. Only $10.9 \%$ completed their studies at university level and/or had a postgraduate degree (Table 1). About one third of the group $32.6 \%$ was illiterate. Only $37.8 \%$ were employed, $21.0 \%$ active smokers and $42.7 \%$ were housewives.

Their mean age group was $52.7 \pm 11.9$ years and more than half of the patients $(59.2 \%)$ were in the age groups $40 \leq 60$ years. The mean duration of diabetes was $8.5 \pm$ 6.3 years. Most $(72.7 \%)$ of them were using oral hypoglycemic drugs, $22.7 \%$ were using insulin either alone or with oral hypoglycemic drugs and only few $(4.7 \%)$ were on diet only.

The mean BMI of the studied group was $29.3 \pm 6.1$. Only $(21.9 \%)$ of the diabetics could be categorized as being within normal range. The remaining was almost equally categorized as overweight or obese. More than one third $(38.3 \%)$ were obese; $22.4 \%$ had mild obesity, and $15.9 \%$ severe obesity (Figure 1). Percentage of severely obese females were almost triple that of males. The housewives were the least to have normal BMI ratio (15.2\%) (Table 2).

Only $14.9 \%$ of the female patients had normal BMI compared to $28.6 \%$ of males, meanwhile it was noticed that the percentage of females who were categorized as being obese grade I $(30.1 \%)$ was double what was recorded in males $(15.0 \%)$ and much higher ratio was remarked for the obesity grade II, where the percentage was almost tripled among females $(24.7 \%)$ when compared to males $(7.4 \%)$ and these observed differences are statistically significant $p<0.001$, (Table 2 ). It was noticed that the percentage of patients who can be consid- 
Table 1. Demographic characteristics of the studied diabetic patients $(n=723)$.

\begin{tabular}{|c|c|c|}
\hline Characteristics & No. & $\%$ \\
\hline \multicolumn{3}{|l|}{ Gender } \\
\hline Male & 367 & 50.8 \\
\hline Female & 356 & 49.2 \\
\hline \multicolumn{3}{|l|}{ Nationality } \\
\hline Saudi & 663 & 91.7 \\
\hline Non Saudi & 60 & 8.3 \\
\hline \multicolumn{3}{|l|}{ Age groups } \\
\hline$<30$ years & 28 & 3.9 \\
\hline $30 \leq 40$ years & 52 & 7.2 \\
\hline $40 \leq 50$ years & 183 & 25.3 \\
\hline $50 \leq 60$ years & 245 & 33.9 \\
\hline $60+$ years & 215 & 29.7 \\
\hline Mean \pm SD & \multicolumn{2}{|c|}{$52.6 \pm 11.9$ years } \\
\hline \multicolumn{3}{|l|}{ Education level } \\
\hline University and postgraduates & 79 & 10.9 \\
\hline Less than university qualifications & 644 & 89.1 \\
\hline \multicolumn{3}{|l|}{ Working status } \\
\hline Employed & 273 & 37.8 \\
\hline Unemployed & 41 & 5.7 \\
\hline Retired & 100 & 13.8 \\
\hline Housewife & 309 & 42.7 \\
\hline
\end{tabular}

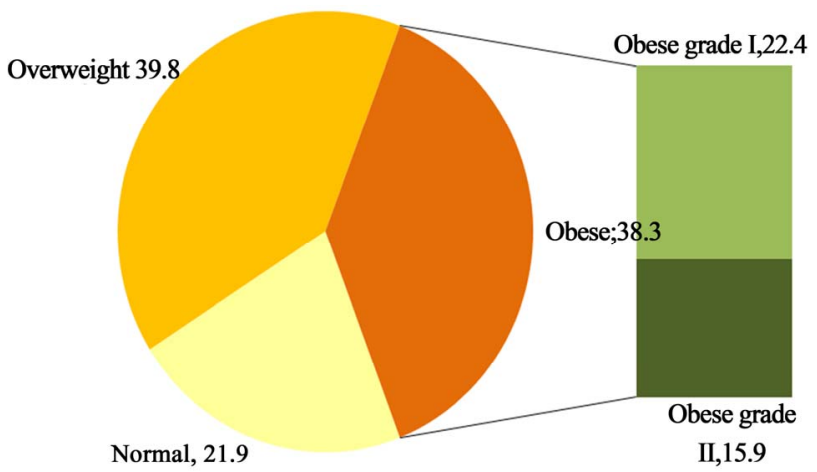

Figures 1. The percentages of various patients' categories according to their body mass index (BMI).

ered to have normal BMI was decreasing steadily towards older age groups till the seventh decade of life where the percentage inversed. Generally, the normal BMI ratio ranged between $35.7 \%$ among those aged $<30$ years and $19.2 \%$ among those in the age group $(50 \leq 60$ years). However, these differences were not statistically significant $\mathrm{p}>0.05$.

The housewives were the least to have normal BMI ratio $(15.2 \%)$ specially when they are compared to those who were employed $(27.1 \%)$ or those who were unemployed $(43.9 \%)$, and these differences were statistically significant $\mathrm{p}<0.001$. Table 2 also shows that there is no significant difference of BMI ratio among the study group according to their education level $\mathrm{p}>0.05$. The majority of females were non-smokers $(90.5 \%)$ compared to $(50.7 \%)$ of males and this difference was statistically significant $p<0.05$. Meanwhile, it was found the non-smokers were the least to have normal BMI ratio $(18.2 \%)$ when compared to the smokers $(29.7 \%)$ and ex-smokers $(37.7 \%)$ and this difference was statistically significant, (Table 2).

When ordinal logistic regression was conducted to examine predictors for obesity among the studied diabetic patients, it is found that being a non-smoker housewife is the significant predicting factor for being obese among the studied diabetic patients $p<0.05$, (Table 3$)$. The various treatment regimens did not correlate to the BMI of the studied sample (Table 4).

\section{Discussion}

According to the International Diabetes Federation IDF's estimates, SA is ranked with the 6th highest prevalence of DM worldwide, and is expected to hold this position for the next 20 years, with a prevalence rate of $20.0 \%$ among 20 - 79-year-old adults [17]. Other countries ranked in the top ten include Kuwait (21.1\%), Lebanon (20.2\%), Bahrain (19.9\%) and the United Arab Emirates (19.2\%) [17]. Much higher prevalence rates of DM in SA were quoted in various published studies $[1,5,12,18,19]$. Ten years ago, Al-Nozha et al. [19] conducted a welldesigned national survey and reported a prevalence rate of $23.7 \%$ in adult Saudis aged $>30$ years $(26.2 \%$ in males versus $21.5 \%$ in females). Higher prevalence rates of DM were reported recently in females more than males below 50 years old; $34.1 \%$ and $25.1 \%$ respectively [12]. The differences among studies can be attributed to the different research methodologies used by researchers. The current study was limited to only known type 2 diabetic patients which is the commonest type of DM and associ- ated high BMI $[18,19]$.

Type 2 DM was already linked to the steady increase in the overweight and obesity rates globally $[2,3]$ particularly in Eastern Mediterranean and GCC regions $[1,5,12,20]$. Obesity is a known modifiable risk factor for type 2 DM $[5,20]$. Prevention and control of obesity in the general population and among diabetics may lead to reduction in the increasing prevalence rates of DM and its complications rates in these countries $[12,20]$. In the current study, only $(21.9 \%)$ of the studied diabetics were 
Table 2. Categorization of the diabetic patients according to their characteristics and calculated BMI $(n=723)$.

\begin{tabular}{|c|c|c|c|c|c|c|c|c|c|}
\hline \multicolumn{10}{|c|}{ Categorization according to calculated BMI } \\
\hline \multirow[b]{2}{*}{ Characteristics } & \multicolumn{2}{|c|}{ Normal } & \multicolumn{2}{|c|}{ Overweight } & \multicolumn{2}{|c|}{ Obese I } & \multicolumn{2}{|c|}{ Obese II } & \multirow{2}{*}{ p. } \\
\hline & No. & $\%$ & No. & $\%$ & No. & $\%$ & No. & $\%$ & \\
\hline \multicolumn{10}{|l|}{ Gender } \\
\hline Male & 105 & $28.6 \%$ & 180 & $49.0 \%$ & 55 & $15.0 \%$ & 27 & $7.4 \%$ & \multirow{2}{*}{$<0.001$} \\
\hline Female & 53 & $14.9 \%$ & 108 & $30.3 \%$ & 107 & $30.1 \%$ & 88 & $24.7 \%$ & \\
\hline \multicolumn{10}{|l|}{ Nationality } \\
\hline Saudi & 141 & $21.3 \%$ & 262 & $39.5 \%$ & 152 & $22.9 \%$ & 108 & $16.3 \%$ & \multirow{2}{*}{0.368} \\
\hline Non Saudi & 17 & $28.3 \%$ & 26 & $43.3 \%$ & 10 & $16.7 \%$ & 7 & $11.7 \%$ & \\
\hline \multicolumn{10}{|l|}{ Age groups (in years) } \\
\hline$<30$ & 10 & $35.7 \%$ & 11 & $39.3 \%$ & 5 & $17.9 \%$ & 2 & $7.1 \%$ & \multirow{5}{*}{0.067} \\
\hline $30 \leq 40$ & 13 & $25.0 \%$ & 20 & $38.5 \%$ & 14 & $26.9 \%$ & 5 & $9.6 \%$ & \\
\hline $40 \leq 50$ & 35 & $19.1 \%$ & 67 & $36.6 \%$ & 50 & $27.3 \%$ & 31 & $16.9 \%$ & \\
\hline $50 \leq 60$ & 47 & $19.2 \%$ & 93 & $38.0 \%$ & 54 & $22.0 \%$ & 51 & $20.8 \%$ & \\
\hline $60+$ & 53 & $24.7 \%$ & 97 & $45.1 \%$ & 39 & $18.1 \%$ & 26 & $12.1 \%$ & \\
\hline \multicolumn{10}{|l|}{ Working status } \\
\hline Employed & 74 & $27.1 \%$ & 120 & $44.0 \%$ & 48 & $17.6 \%$ & 31 & $11.4 \%$ & \multirow{4}{*}{$<0.001$} \\
\hline Unemployed & 18 & $43.9 \%$ & 16 & $39.0 \%$ & 4 & $9.8 \%$ & 3 & $7.3 \%$ & \\
\hline Retired & 19 & $19.0 \%$ & 55 & $55.0 \%$ & 18 & $18.0 \%$ & 8 & $8.0 \%$ & \\
\hline Housewife & 47 & $15.2 \%$ & 97 & $31.4 \%$ & 92 & $29.8 \%$ & 73 & $23.6 \%$ & \\
\hline \multicolumn{10}{|l|}{ Education level } \\
\hline University+ & 16 & $20.3 \%$ & 37 & $46.8 \%$ & 12 & $15.2 \%$ & 14 & $17.7 \%$ & \multirow{2}{*}{0.368} \\
\hline$<$ University & 142 & $22.0 \%$ & 251 & $39.0 \%$ & 150 & $23.3 \%$ & 101 & $15.7 \%$ & \\
\hline \multicolumn{10}{|l|}{ Smoking status } \\
\hline Smoker & 47 & $29.7 \%$ & 73 & $46.2 \%$ & 24 & $15.2 \%$ & 14 & $8.9 \%$ & \multirow{3}{*}{$<0.001$} \\
\hline Non-smoker & 91 & $18.2 \%$ & 187 & $37.3 \%$ & 126 & $25.1 \%$ & 97 & $19.4 \%$ & \\
\hline Ex-smoker & 20 & $37.7 \%$ & 19 & $35.8 \%$ & 11 & $20.8 \%$ & 3 & $5.7 \%$ & \\
\hline
\end{tabular}

Table 3. Ordinal logistic regression for predictors of obesity among diabetic patients.

\begin{tabular}{|c|c|c|c|c|c|c|c|c|}
\hline & & \multirow{2}{*}{ Estimate } & \multirow{2}{*}{ Std. Error } & \multirow{2}{*}{ Wald } & \multirow{2}{*}{ d.f. } & \multirow{2}{*}{ Sig. } & \multicolumn{2}{|c|}{$95 \%$ Confidence Interval } \\
\hline & & & & & & & Lower Bound & Upper Bound \\
\hline \multirow{3}{*}{ Threshold } & [Overweight] & $-1.925-$ & 0.378 & 25.942 & 1 & 0.000 & $-2.665-$ & $-1.184-$ \\
\hline & [Obese I] & $-0.020-$ & 0.372 & 0.003 & 1 & 0.957 & $-0.749-$ & 0.708 \\
\hline & [Obese II] & 1.288 & 0.374 & 11.837 & 1 & 0.001 & 0.554 & 2.022 \\
\hline \multirow{9}{*}{ Location } & {$[$ Gender $=$ Female $]$} & 1.535 & 0.294 & 27.243 & 1 & 0.000 & 0.959 & 2.111 \\
\hline & {$[$ Gender $=$ Male $]$} & $0^{\mathrm{a}}$ & - & - & 0 & - & - & - \\
\hline & [Non-smoker] & 0.507 & 0.181 & 7.818 & 1 & 0.005 & 0.152 & 0.863 \\
\hline & [Ex-smoker] & $-0.227-$ & 0.294 & 0.594 & 1 & 0.441 & $-0.803-$ & 0.350 \\
\hline & [Smoker] & $0^{\mathrm{a}}$ & - & - & 0 & - & - & - \\
\hline & [Housewife] & 0.731 & 0.169 & 18.838 & 1 & 0.000 & 0.401 & 1.062 \\
\hline & [Retired] & $-0.856-$ & 0.319 & 7.211 & 1 & 0.007 & $-1.481-$ & $-0.231-$ \\
\hline & [Unemployed] & 0.028 & 0.216 & 0.017 & 1 & 0.897 & $-0.395-$ & 0.451 \\
\hline & [Employed] & $0^{\mathrm{a}}$ & - & - & 0 & - & - & - \\
\hline
\end{tabular}


Table 4. Categorization of the diabetic patients according to the type of treatment and calculated BMI $(n=723)$.

\begin{tabular}{|c|c|c|c|c|c|c|c|c|c|}
\hline \multirow[b]{3}{*}{ Type of treatment } & \multicolumn{8}{|c|}{ Categorization according to calculated BMI } & \multirow{3}{*}{$\mathrm{p}$} \\
\hline & \multicolumn{2}{|c|}{ Normal } & \multicolumn{2}{|c|}{ Overweight } & \multicolumn{2}{|c|}{ Obese I } & \multicolumn{2}{|c|}{ Obese II } & \\
\hline & No. & $\%$ & No. & $\%$ & No. & $\%$ & No. & $\%$ & \\
\hline Diet only & 7 & $20.6 \%$ & 15 & $44.1 \%$ & 10 & $29.4 \%$ & 2 & $5.9 \%$ & \\
\hline Oral hypoglycemic only & 35 & $19.6 \%$ & 63 & $35.2 \%$ & 45 & $25.1 \%$ & 36 & $20.1 \%$ & \\
\hline Diet and oral hypoglycemic & 79 & $22.8 \%$ & 141 & $40.6 \%$ & 72 & $20.7 \%$ & 55 & $15.9 \%$ & \\
\hline Oral hypoglycemic and insulin & 11 & $22.0 \%$ & 25 & $50.0 \%$ & 9 & $18.0 \%$ & 5 & $10.0 \%$ & 0.427 \\
\hline Diet, oral hypoglycemic and insulin & 7 & $14.3 \%$ & 23 & $46.9 \%$ & 10 & $20.4 \%$ & 9 & $18.4 \%$ & \\
\hline Insulin alone & 11 & $34.4 \%$ & 12 & $37.5 \%$ & 6 & $18.8 \%$ & 3 & $9.4 \%$ & \\
\hline Diet and insulin & 8 & $25.0 \%$ & 9 & $28.1 \%$ & 10 & $31.2 \%$ & 5 & $15.6 \%$ & \\
\hline
\end{tabular}

in their ideal range of body weight. This high prevalence rate of obesity among diabetics in western SA is similar to what has been reported from Eastern SA [13] and central SA [12]. The objective of this work is to identify the predictors for developing obesity among diabetics aiming to target those at higher risk in future educational and nutritional program. According to the predictors studied, being a non-smoker housewife is the significant predicting factor for being obese among the studied diabetic patients. The latter predictors i.e. female, married and housewife were already been addressed in the literature as isolated predictors. The high prevalence of obesity rather than overweight in diabetic females was already been reported in few studies conducted on various groups of patients $[4,5,12,13]$. The current results support the findings of similar previous studies which reported higher prevalence rate of obesity in diabetic women [5, 12,13]. Very few studies tested the differences between males and females. In a Saudi national survey, more women than men were obese, $23.6 \%$ compared to $14.2 \%$. In contrast, prevalence of overweight was $30.7 \%$ for males and $28.4 \%$ for females [4]. Current results also indicate that diabetic housewives who are $\mathrm{k}$ unemployed and largely inactive are more likely to develop obesity. These findings among female diabetic patients are similar to that reported in non-diabetic Saudis which reported high prevalence rates of obesity among healthy, married, middle aged, multiparous housewives living in rural areas $[10,11]$.

The prevalence of smoking in the studied sample is $21 \%$ which is double the rate reported on a similar group of patients from Riyadh $11 \%$ [21]. In the studied sample, it is found that being a non-smoker diabetic is the third predictor for being an obese diabetic. This finding is really interesting but difficult to be explained. The association between smoking and type $2 \mathrm{DM}$ was reviewed in a recent prospective Finnish study on non-diabetics and researchers identified smoking as a risk factor for type 2 diabetes independently of BMI and physical activity [22]. So, quitting smoking decreases the risk of type 2 diabetes to close to those in non-smokers and will result in other health benefits, too [22]. On the other hand, Korean researchers concluded that smoking frequency and cigarette consumption had positive effects with regard to weight loss in adolescents. However, smoking has negative side effects on general health, including an increase in abdominal fat and morbidity rates of obesity-related diseases [23]. This dilemma needs further investigations in view of the scanty literature on these contradicting effects of smoking in diabetic patients.

In the meantime, non-smokers housewives should be considered as the high risk group of developing obesity among diabetic patients and should be targeted by future educational and prevention program. Their healthy habit of non-smoking should be certainly encouraged. However, these non-smokers' housewives should be aware that they are at higher risk for developing obesity and should therefore be more cautious of their food intake and perform more physical activities inside and outside their houses which may be quite difficult in hot conservative countries such as SA and adjacent GCC countries.

In conclusion, prevention and educational program should identify and target those diabetic patients who are at higher risk of developing obesity. In the current study, this group was defined as non-smokers diabetic housewives. Further research is needed to explore the effects of smoking on obese diabetic patients.

\section{Acknowledgments}

The author would like to thank Dr. Adel Ibrahim who did the statistical analysis, Prof. H. Alzahrani for editing the final manuscript and "Mohammad Hussein Alamoudi Chair for Diabetic Foot Research" at King Abdulaziz University for supporting the study. 


\section{REFERENCES}

[1] L. Alhyas, A. McKay, A. Balasanthiran and A. Majeed, "Prevalences of Overweight, Obesity, Hyperglycaemia, Hypertension and Dyslipidaemia in the Gulf: Systematic Review," Journal of the Royal Society of Medicine, Vol. 2, No. 7, 2011, p. 55.

[2] Y. Wang, H. J. Chen, S. Shaikh and P. Mathur, "Is Obesity Becoming a Public Health Problem in India? Examine the Shift from under- to Overnutrition Problems over Time," Obesity Reviews, Vol. 10, No. 4, 2009, pp. 456474. doi:10.1111/j.1467-789X.2009.00568.x

[3] M. L. Baskin, J. Ard, F. Franklin and D. B. Allison, "Prevalence of Obesity in the United States," Obesity Reviews, Vol. 1, No. 1, 2005, pp. 5-7. doi:10.1111/j.1467-789X.2005.00165.x

[4] A. I. Al-Othaimeen, M. Al-Nozha and A. K. Osman, "Obesity: An Emerging Problem in Saudi Arabia. Analysis of Data from the National Nutrition Survey," Eastern Mediterranean Health Journal, Vol. 2, No. 2, 2007, pp. 441-448.

[5] M. A. El-Hazmi and A. S. Warsy, "Prevalence of Overweight and Obesity in Diabetic and Non-Diabetic Saudis," Eastern Mediterranean Health Journal, Vol. 6, No. 2-3, 2000, pp. 276-282.

[6] A. O. Musaiger, "Socio-Cultural and Economic Factors Affecting Food Consumption Patterns in the Arab Countries," Journal of the Royal Society of Health, Vol. 113, No. 2, 1993, pp. 68-74. doi: $10.1177 / 146642409311300205$

[7] B. A. Bakhotmah, "The Puzzle of Self-Reported Weight Gain in a Month of Fasting (Ramadan) among a Cohort of Saudi Families in Jeddah, Western Saudi Arabia," Nutrition Journal, Vol. 10, 2011, p. 84. doi:10.1186/1475-2891-10-84

[8] F. M. Midhet, A. A. Al-Mohaimeed and F. K. Sharaf, "Life-Style Related Risk Factors of Type 2 Diabetes Mellitus in Saudi Arabia," Saudi Medical Journal, Vol. 31, No. 7, 2010, pp. 768-774.

[9] H. M. Al-Hazzaa, "Prevalence of Physical Inactivity in Saudi Arabia: A Brief Review," East Mediterranean Health Journal, Vol. 10, No. 4-5, 2004, pp. 663-670.

[10] S. A. Al-Shammari, T. A. Khoja, M. A. Al-Maatouq and L. A. Al-Nuaim, "High Prevalence of Clinical Obesity among Saudi Females: A Prospective, Cross-Sectional Study in the Riyadh Region," Journal of Tropical Medicine \& Hy-giene, Vol. 3, No. 3, 1994, pp. 183-188.

[11] J. S. Al-Malki, M. H. Al-Jaser and A. S. Warsy, "Overweight and Obesity in Saudi Females of Childbearing Age," International Journal of Obesity and Related Metabolic Disorders, Vol. 27, No. 1, 2003, pp. 134-139. doi:10.1038/sj.ijo.0802181

[12] K. A. Alqurashi, K. S. Aljabri and S. A. Bokhari, "Prevalence of Diabetes Mellitus in a Saudi Community," Annals of Saudi Medicine, Vol. 31, No. 1, 2011, pp. 19-23. doi:10.4103/0256-4947.75773

[13] K. M. Mugharbel and M. A. Al-Mansouri, "Prevalence of Obesity among Type 2 Diabetic Patients in Al-Khobar Primary Health Care Centers," Journal of Family and Community Medicine, Vol. 10, No. 2, 2003, pp. 49-53.

[14] http://apps.who.int/bmi/index.jsp?introPage=intro_3.html 2012.

[15] WMA, "Declaration of Helsinki-Ethical Principles for Medical Research Involving Human Subjects," 2012. http://www.wma.net/en/30publications/10policies/b3/

[16] C. K. Chen and J. Hughes, "Using Ordinal Regression Model to Analyze Student Satisfaction Questionnaires," Association for Institutional Research, Vol. 1, 2004, pp. 1-13.

[17] "International Diabetes Federation: IDF Diabetes Atlas," 5th Edition, 2012.

http://www.idf.org/diabetesatlas/5e/the-global-burden

[18] T. A. Elhadad, A. A. Al-Amoudi and A. S. Alzahrani, "Epidemiology, Clinical and Complications Profile of Diabetes in Saudi Arabia: A Review," Annals of Saudi Medicine, Vol. 27, No. 4, 2007, pp. 241-250. doi:10.4103/0256-4947.51484

[19] M. M. Al-Nozha, M. A. Al-Matouq, Y. Y. Al-Mazrou, S. S. Al-Harthi, M. R. Arafah, M. Z. Khalil, N. B. Khan, A. Al-Khadra, K. Al-Marzouki, M. S. Nouh, M. Abdullah, O. Attas, M. S. Al-Shahid and A. Al-Mobeireek, "Diabetes Mellitus in Saudi Arabia," Saudi Medical Journal, Vol. 25, No. 11, 2004, pp. 1603-1610.

[20] A. Musaiger, "Overweight and Obesity in Eastern Mediterranean Region: Prevalence and Possible Causes," Journal of Obesity, Vol. 2011, 2011, Article ID: 407237.

[21] R. A. Salman and K. A. Al-Rubeaan, "Incidence and Risk Factors of Hypertension among Saudi Type 2 Diabetes Adult Patients: An 11-Year Prospective Randomized Study," Journal of Diabetes Complications, Vol. 23, No. 2, 2009, pp. 95-101. doi:10.1016/j.jdiacomp.2007.10.004

[22] K. Patja, P. Jousilahti, G. Hu, T. Valle, Q. Qiao and J. Tuomilehto, "Effects of Smoking, Obesity and Physical Activity on the Risk of Type 2 Diabetes in Middle-Aged Finnish Men and Women," Journal of Internal Medicine, Vol. 258, No. 4, 2005, pp. 356-362. doi:10.1111/j.1365-2796.2005.01545.x

[23] K. Jong-Hyuck and S. Wi-Young, "Association of Smoking Frequency and Cigarette Consumption with Obesity in Korean Adolescents," Bratislava Medical Journal, Vol. 113, No. 10, 2012, pp. 599-603. 